\title{
Evaluation of Land Resources Pressure in the districts of Huhhot, Baotou and Erdos Based on GIS Technology
}

\author{
Peiling $\mathrm{Li}^{1}$, Xiaojun Huang ${ }^{1,2,3}$, Yuhai Bao ${ }^{1,2}$, Shan Yu ${ }^{1,2}$ \\ ${ }^{1}$ College of Geographical Science, Inner Mongolia Normal University, Huhhot 010022, China \\ ${ }^{2}$ Key Laboratory of Remote Sensing \& Geography Information System, Inner Mongolia Normal \\ University, Huhhot 010022, China \\ ${ }^{3}$ Inner Mongolia Key Laboratory of Disaster and Ecological Security on the Mongolia plateau, \\ Inner Mongolia Normal University, Huhhot 010022, China
}

\section{基于 GIS 技术的呼包鄂地区土地资源压力评价 李佩玲 ${ }^{1}$, 黄晓君 ${ }^{1,2,3}$,包玉海 ${ }^{1,2}$, 玉山 ${ }^{1,2}$, \\ 1 内蒙古师范大学地理科学学院, 呼和浩特 010022 , 中国 2 内蒙古自治区遥感与地理信息系统重点实验室, 呼和浩特 010022 , 中国 ${ }^{3}$ 内蒙古自治区蒙古高原灾害与生态安全研究重点实验室, 呼和浩特 010022 , 中国}

\begin{abstract}
This article uses districts of Huhhot, Baotou and Erdos as the research area, establishes the evaluation index system of land resources pressure, and evaluates the pressure of land resources in the study area and analyzes the causes through spatial superposition analysis method of GIS software platform. The research indicates that the pressure on land resources is greater in areas such as Guyang County, Qingshan District, Kundulun District, Wuchuan County, Qingshuihe County, etc,the areas with medium pressure are Tumote Zun Banner, Saihan District, and Helingeer County, Zhungeer Banner, Dongsheng District and Kangbashi New District,the areas of low pressure include Darhan Maomingan United Banner, Dalate Banner, Etuokeqian Banner, etc.The research results provide a reference for the future land development and utilization pattern planning inthe districts of Huhhot, Baotou and Erdos.
\end{abstract}

Key words: the districts of Huhhot Baotou and Erdos;Land pressure evaluation;Construction and development suitability;Suitable for construction and development;GIS spatial analysis

摘要

本文以呼包鄂为研究区, 建立土地资源 压力评价指标体系, 通过 GIS 软件平台空间 叠加分析方法, 评价研究区土地资源压力并 分析成因。研究结果表明, 土地资源压力较 大区域有固阳县、青山区、昆都仑区、武川 县、清水河县等, 压力中等区域为土默特左 旗、赛罕区、和林格尔县、准格尔旗、东胜 区和康巴什新区, 压力小的区域有达尔罕茂 明安联合旗、达拉特旗、鄂托克前旗等。本 文研究结果为呼包鄂地区未来土地开发利 用格局的规划提供参考。

关键词: 呼包鄂地区; 土地压力评价; 建设 开发适宜性; 适宜建设开发程度; GIS 空间 分析

土地资源是具有一定空间范围的自然 综合体, 由全部相互关联的各自然地理要素 
共同构成, 包括人类活动直接或间接影响。 随着中国城市化的迅速发展和人口数量剧 增, "人”与"地”的关系日趋紧张。土地资源 评价可以反映区域目前的土地资源条件对 未来人口增长和城市化加速推进的支撑能 力, 对土地的合理、科学规划利用以及土地 政策、人口政策的制订有重要意义。

自 20 世纪 60 年代以来, 美国、澳大利 亚等国家均开展了土地分类和土地潜力分 类方面的了地评价工作。如 1961 年, 美国 为查明和保护最适合农业耕作的土地, 对全 国的土地进行潜力评价; 至 20 世纪 70 年代 后, 联合国陆续颁布了土地适宜性评价方 案、农业生态区方法、持续土地利用评价等 各类土地评价方, 为土地资源评价的全球性 开展打下良好基础。随着计算机技术和"3S” 技术的快速发展, 土地压力评价的方法呈现 出多样化趋势, 其中基于 GIS 技术的土地资 源压力评价方法逐渐成为该领域的主流。20 世纪 80 年代后期以来, 我国的土地资源评 价精度在土地资源信息系统的建立和 GIS 技 术的发展成熟下不断提高, 取得了一系列成 果: 《全国 1: 100 万土地资源图》、农业 部的第二次土壤普查将土地分为 8 级; 《全 国耕作类型区、耕地地力等级划分》方案等。

随着计算机技术和“3S”技术的快速发 展, 土地压力评价的方法呈现出多样化趋 势, 其中基于 GIS 技术的土地资源压力评价 方法逐渐成为该领域的主流。GIS 技术超高 的评价速率和精准性不仅节省了时间和人 力, 还避免了评价过程中人为因素误差的影 响, 具有较高精确度。20 世纪 90 年代, 世 界级的土壤与土地数据系统、土地自动评价 系统的建立, 开启了土地评价从定性描述到 定量化研究的新时代。2011 年, 王玲采用特 尔菲法选择了六大类 19 个评价指标, 以此 构建了适合农五师的耕地地力评价指标体 系, 在基于 GIS 和 RS 技术的支持下, 结合 层次分析法和模糊综合评判法对干旱区的 绿洲耕地质量进行评价, 将该研究区域的耕 地分为五个等级[1]。2017 年, 张洪等人以大 理市为研究区, 建立了包括地形地貌、生态 环境、地质条件等五个方面 24 各影响因子 的评价指标体系, 将传统的多因素综合评价
模型与 CA 模型原理进行融合, 利用 GIS 的 空间分析功能, 针对该地低丘缓坡利用适宜 性做出评价[2]。2018 年, 龚亚男, 韩书成等 人分别构建了相应于耕地、原地、林地和牧 草地的评价指标体系, 运用多因素分析法、 深层次分析法一 GIS 技术结合的方法, 对安 徽省铜陵县横冲流域的土地适宜性进行评 价[3]。

从以上学者的研究结果不难看出, 基于 GIS 技术进行土地资源评价时, 都要结合传 统的研究方法。因此, 本文以呼包鄂地区为 研究区域, 在 GIS 技术支持的基础下, 结合 限制系数计算法、聚类分析法, 构建了土地 资源压力评价指标体系, 对呼包鄂地区各旗 县的土地资源压力程度进行评价。

\section{1 数据与方法}

\section{1 数据来源}

本文所用的数据来源年份为 2014 年, 包括国土资源厅提供的内蒙古自治区地质 灾害已发生程度分区图 (1：150万) 中的突 发地质灾害数据、高产耕地数据中的永久基 本农田数据、地震局地震断裂带数据外扩 $1 \mathrm{~km}$ 数据、环保厅的自然保护区数据和全国 第一次地理国情普查数据中的荒漠、常年 河、常年湖、水库、时令河、时令湖、干涸 河、干涸湖、人工草地、耕地、天然草地、 园地、林地数据和 DEM 数据提取的坡度数 据, 其中坡度与突发地质灾害数据为栅格数 据, 其余为矢量数据, 经分析处理后转为栅 格数据。所有数据的分辨率均为 $1000 \times 1000 \mathrm{~m}$ 。

\section{2 研究方法}

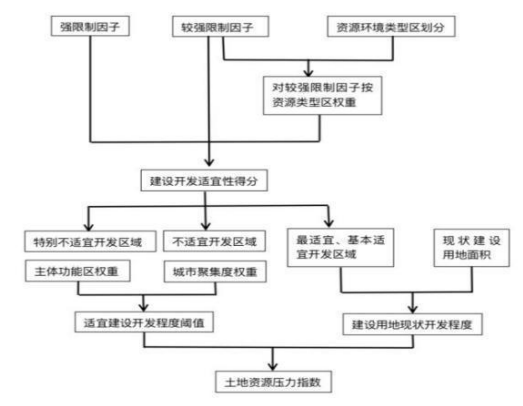


首先在所获数据中篮选出建立指标体 系所必须的评价指标, 并进行适宜性赋值, 赋值依据为国家发展和改革委员会文件, 关 于引发《资源环境承载力监测预警技术方法 (试行)》的通知, 为提高评价精度, 对于 评价指标中一般农用地的赋值结合专家打 分法做了进一步细化赋值, 详见表 1 。

\begin{tabular}{|c|c|}
\hline 要素 & 适宜性赋值 \\
\hline 永久基本农田 & 0 \\
\hline 其他 & 1 \\
\hline 国家级、自治区级自然保护区 & 0 \\
\hline 其他 & 1 \\
\hline 戈壁、荒漠等 & 0 \\
\hline 其他 & 1 \\
\hline 地震设防区 & 40 \\
\hline 其他 & 100 \\
\hline 林地 & 20 \\
\hline 高于平均等耕地、人工草地 & 40 \\
\hline 低于平均等耕地、天然草地 & 60 \\
\hline 园地 & 80 \\
\hline 其他 & 100 \\
\hline 林地 & 10 \\
\hline 天然草地 & 30 \\
\hline 高于平均等耕地、人工草地 & 40 \\
\hline 低于平均等耕地 & 60 \\
\hline 园地 & 80 \\
\hline 其他 & 100 \\
\hline $\begin{array}{l}\text { 高于半均等耕地、低于半均等耕 } \\
\text { 地 }\end{array}$ & 20 \\
\hline 天然草地 & 30 \\
\hline 人工草地 & 40 \\
\hline 林地 & 60 \\
\hline 园地 & 80 \\
\hline 其他 & 100 \\
\hline $\begin{array}{l}\text { 高于平均等耕地、低于平均等耕 } \\
\text { 地 }\end{array}$ & 20 \\
\hline 人工草地、林地 & 40 \\
\hline 天然草地 & 60 \\
\hline 园地 & 80 \\
\hline 其他 & 100 \\
\hline $15^{\circ}$ 以上 & 40 \\
\hline $8^{\circ} \sim 15^{\circ}$ & 60 \\
\hline $2^{\circ} \sim 8^{\circ}$ & 80 \\
\hline $0^{\circ} \sim 2^{\circ}$ & 100 \\
\hline 高易发区 & 40 \\
\hline 中易发区 & 60 \\
\hline 低易发区 & 80 \\
\hline 无地质灾害风险 & 100 \\
\hline 重要蓄滞洪区 & 40 \\
\hline 一般蓄滞洪区 & 60 \\
\hline 蓄滞洪保留区 & 80 \\
\hline 其他 & 100 \\
\hline
\end{tabular}

结合经济发展水平、生态文明建设和主 体功能定位, 可进行资源环境类型区划分, 详见表 2 。在此基础上, 建立由土地建设开 发适宜性、现状建设用地开发程度、适宜建 设开发程度和土地资源压力指数构成的评 价指标体系, 通过 GIS 软件平台空间叠加分 析方法, 评价研究区土地资源压力并分析成 因。

表 2 资源类型区划分

\begin{tabular}{cl}
\hline 类型 & \multicolumn{1}{c}{ 分布范围 } \\
\hline & 新城区、回民、、玉泉区、 \\
& 赛罕区、托克托县、和林格尔县、 \\
& 土默特左旗; 东河区、昆都仑区、 \\
城市工 & 青山区、九原区、石拐区、白云鄂 \\
矿型 & 博矿区、东胜区、伊金霍洛旗、准 \\
& 格尔旗、鄂托克旗、鄂托克前旗、 \\
& 乌审旗、达拉特旗、杭锦旗、康巴 \\
& 什新区 \\
生态功 & 清水河县; 达尔罕茂明安联合旗、 \\
能型 & 固阳县; ; \\
农蓄产 & 呼和浩特市: 武川县 \\
品 & 包头市: 土默特右旗; \\
主产型 & \\
\hline
\end{tabular}

\section{2. 研究结果与分析}

\section{1 呼包鄂地区土地压力评价}

\subsection{1 土地建设开发适宜性评价}

达尔罕茂明安联合旗中北部、杭锦旗南 部与鄂托克旗过渡地带、鄂托克旗中部和鄂 托克前旗少部分区域为最适宜、基本适宜开 发区域, 建设用地开发适宜性较好。包头市 区与呼和浩特市区人口密度大, 现状建设用 地开发程度高; 清水河县地处黄土高原丘陵 区, 属生态脆弱区; 固阳县资源匮乏, 土地 资源质量较差; 土默特左旗北部地貌类型为 难以利用的山地, 南部为优质耕地, 这两处 不利于建设用地开发; 托克托县、武川县、 土默特右旗和杭锦旗北部的黄河南岸冲积 平原均有大面积不能作为建设用地的耕地, 以上地区的建设开发适宜性为特别不适宜。 其余地区的建设开发适宜性结果为不适宜。 


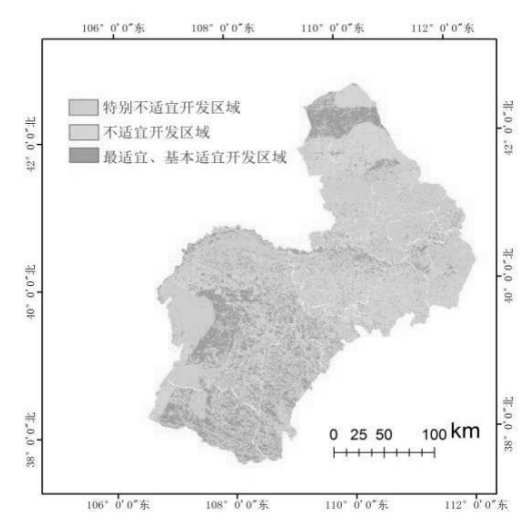

图 1 土地建设开发适宜性评价

\subsection{2 现状建设开发程度评价}

现状开发程度最大的四个区域为回民 区、玉泉区、青山区和昆都仑区。固阳县、 石拐区、东河区、九原区、武川县、新城区、 赛罕区、和林格尔县以及康巴什新区的开发 程度中等。其余 14 各旗、县、区的开发程 度最小。

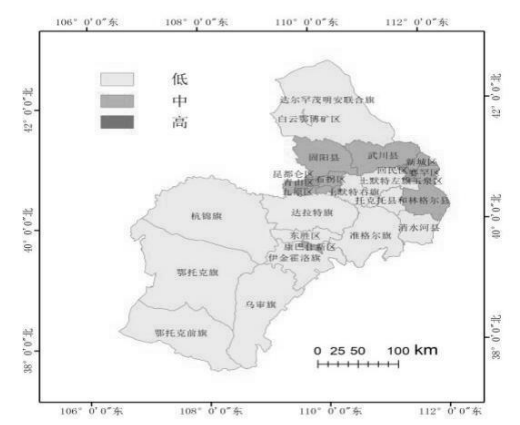

图 2 现状建设开发程度评价

\subsection{3 土地资源压力评价}

呼包鄂地区共 27 个旗县（市、区）中, 有 12 个旗县 (市、区) 的土地资源压力大, 分别是包头五市辖区、固阳县、土默特右旗、 武川县、新城区、回民区、玉泉区和清水河 县, ; 土地资源压力中等的有 6 个旗县 (市、 区）, 分别是土默特左旗、赛罕区、和林格 尔县、准格尔旗、东胜区和康巴什新区; 土 地资源压力等级为小的有 9 个旗县 (市、区), 分别是达尔罕茂明安联合旗、白云鄂博矿
区、托克托县和鄂尔多斯其余 6 旗。总体来 说包头市压力最大, 呼和浩特次之, 鄂尔多 斯市压力最小。呼包鄂地区的面临的土地资 源压力情况复杂, 与区域内地貌类型复杂多 样有密切联系。

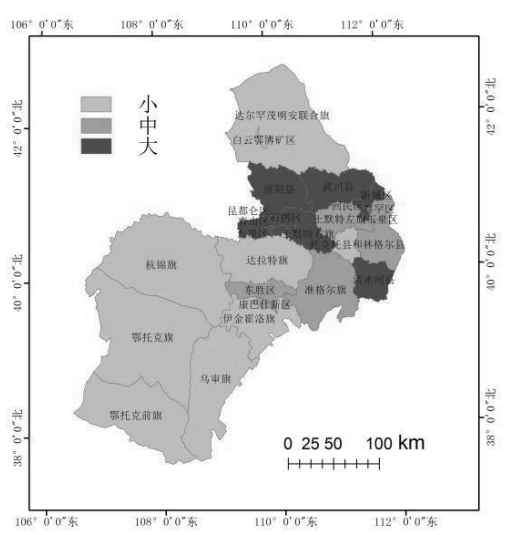

图 3 土地资源压力评价

\section{2 呼包鄂地区土地资源压力成因分析}

土地资源压力指数影响因素较多, 限制 建设用地开发的主导约束条件也各不相同, 因此在结果分析中要运用具体地区具体分 析、部分与整体相联系的方法。

呼包鄂区域市辖区的人口密度大、现状 建设用地开发程度高是土地资源压力大的 主要原因; 清水河县与固阳县境内土地资源 质量差, 水资源匮乏且时空分布不均, 经济 发展落后, 生产经营方式粗放, 地区生态环 境脆弱[4], 土地资源压力大; 武川县与土默 特旗境内均有大面积耕地, 不同的是武川县 多为地势较高的陡坡旱地, 降水量少而蒸发 量大 [5], 区域水土不协调, 而土默特右旗水 资源储量丰富, 耕地面积大, 是国家优质产 粮大县[6], 土地资源压力来自建设用地供应 不足; 康巴什新区城市现状建设开发程度较 高, 土地资源压力大, 可继续用于建设开发 的土地资源严重不足。

在土地资源压力中等的区域中, 土默特 左旗境内水资源、矿产资源丰富, 产业结构 趋于合理[7], 发展空间较大; 和林格尔县形 地貌多样, 山川丘皆备, 对土地资源开发利 
用有一定制约作用 [8], 现状建设用地开发程 度中等; 东胜区是鄂尔多斯市经济文化中 心, 人口密度大, 建设用地开发程度较大; 准格尔旗境内水资源丰富, 可满足当地生产 生活需要, 煤炭及煤层气的储量可观, 经济 发展对矿产资源开发的依赖程度高。

托克托县地处大青山南坡的土默川平 原上, 耕地较多, 该县利用区位优势积极调 整产业结构, 由一产业主导型向一二三产业 协调型转变, 现状建设用地开发程度低, 土 地资源压力小。达尔罕茂明安联合旗土地面 积辽阔, 戈壁面积较大, 生态环境脆弱, 是 我国实施风沙源治理保护建设工程区域[9], 尽管现状开发程度很低, 土地资源压力小。 白云鄂博矿区全境被达茂旗环绕, 是呼包鄂 地区唯一的县 (区) 级工矿区, 蕴藏着占世 界已探明总储量 $2 / 5$ 以上的稀土矿物 [10]等 各种矿产资源, 适宜建设开发程度较高, 现 状建设用地开发程度低, 土地资源压力小。 鄂尔多斯市西部六旗[11][12][13]草场广布, 人口密度小, 煤炭、天然气、石油等矿产资 源丰富, 是“西气东输”、“西煤东运”工程的 输出地, 现状开发程度低, 土地资源压力小, 其中达拉特旗区位优势突出, 极具经济发展 潜力。

\section{3. 结束语}

本文以呼包鄂为研究区, 建立土地资源 压力评价指标体系, 通过GIS软件平台空间 叠加分析方法, 对该呼包鄂地区的土地资源 压力进行评价。研究发现, 包头市的工业发 展历时较长, 基础深厚, 整体经济实力较强, 土地资源压力最大; 呼和浩特市凭借优越的 区位条件积极调整产业结构, 实现了一、二、 三产业协调发展, 经济增长迅速, 整体土地 资源压力适中; 鄂尔多斯市境内草场广布, 农牧交错的发展方式一直以来是当地的主 要经济发展方式, 土地资源压力小。但随着 大量石油、天然气、煤炭资源储量的探明, 鄂尔多斯市转型为资源型城市, 城镇、居民 工矿用地面积逐年扩大, 草场、耕地面积均 有不同幅度的缩减, 给原本脆弱的草原生态 系统带来较大挑战，土地荒漠化问题日益突 出, 在区域发展过程中要注意土地利用的合
理性, 合理安排基础设施、生态建设和优势 特色产业用地, 促进各区域协调发展, 各旗 县 (市、区) 都能依托自身独特的自然、区 位条件, 建立恰合当地生态环境的经济发展 模式。依靠科技手段对生产要素加以整合升 级, 以科学技术为指导, 把经济建设、资源 整合和生态建设相结合，建立新型的呼包鄂 地区工农业生产体系, 探索用地新空间, 解 决用地紧张的现状。

\section{参考文献}

[1] 王玲.基于 GIS 和 RS 的干旱区绿洲耕地 质量评价方法及应用研究. 石河子大 学, 2011 .

[2] 张洪,曹京,董世杰.基于 GIS 的低丘缓坡 土地利用建设适宜性评价--以大理市为 例.安徽农业科学,2017,45(6):212-217.

[3] 龚亚男,基于 GIS 的土地适宜性评价研 究--以安徽省铜陵县横冲流域为例. 经 济师,2018,3:26-28.

[4] 李鹏, 共享发展理念视角下清水河县稳 定脱贫研究.内蒙古师范大学, 2017 .

[5] 周瑞平, 吴全, 余艳华等. 呼和浩特市土地 综合承载力区域差异分析. 内蒙古师范 大学学报 (自然科学汉文 版),2013,42(5):590-597.

[6] 张卿.土默特右旗未利用土地开发潜力 评价.内蒙古师范大学, 2014 .

[7] 贾俊青.土默特左旗土地利用空间规划 研究.内蒙古师范大学,2011.

[8] 荆新全.基于 GIS 的土地适宜性评价及 其应用研究--以和林格尔县为例.内蒙 古师范大学,2011.

[9] 贡吉玛.达尔罕茂明安联合旗草原类型 空间分布的特征. 内蒙古草 业,2011,23(3):53-56.

[10] 白淑英,朱倩文等.白云鄂博矿区生态退 化研究. 生态与农村环境学 报,2016,32(3):367-373.

[11] 德英, 敖特根, 布仁吉雅. 鄂托克前旗草地 资源评价.内蒙古草业,2006,18(1):30-32.

[12] 包苏雅,银山,阿拉腾图雅.鄂托克旗土地 利用动态变化及其影响要素分析.内蒙 古林业科技,2010,36(4):71-75. 
[13] 布仁吉日嘎拉. 内蒙古杭锦旗土地可持 续利用研究.内蒙古师范大学, 2003 .

[14] Li X H, Wu W J, Lv D B, et al. Research on risk assessment and regionalization of forest and grassland fires. Journal of Risk Analysis and Crisis Response, 2012, 2(1): 69-77. 